\title{
FAILURE ANALYSIS AND REDESIGNING OF INTERNAL FIXATION SCREWS
}

\author{
Seshasai Srihari Hanuma Ravinuthala \\ Department of Metallurgical engineering \\ JNTU-K (UCEV), Vizianagaram, \\ Andhra Pradesh, India
}

\author{
B Sai Sri Harshita \\ Department of Botany \\ Andhra university, Visakhapatnam, \\ Andhra Pradesh, India
}

\begin{abstract}
Its highly impossible for false proofing the super structures or mechanisms or the metallurgical methods after installation so they are perfectly engineered and dispatched only after a series of quality checks which has a proper methodology. If this is the scenario with the non living structure's components if they were engineered without errors. There must be some more intensity with the living organisms. living organisms are not engineered but the engineering of the ailments or aids which support the life of living organism must be error free and perfect also must be ready to use. In this context it's pity that there is no perfect operational procedure for internal fixation of fractures this thesis Is focused on that area and aimed to derive a reliable design of internal fixation screw which is designed in contrast with conventional screw This project is stimulation out from two case studies of operational failure implant removal.
\end{abstract}

\section{Keywords - Internal fixation, Screws}

\section{INTRODUCTION}

Chemistry of Titanium The first titanium mineral, a black sand called menachanite, was discovered in 1791 in Cornwall by the Reverend William Gregor. He analysed it and deduced it was made up of the oxides of iron and an unknown metal, and reported it as such to the Royal Geological Society of Cornwall. In 1795, the German scientist Martin Heinrich Klaproth of Berlin investigated a red ore known as Schörl from Hungary. This is a form of rutile ( $\mathrm{TiO} 2)$ and Klaproth realised it was the oxide of a previously unknown element which he named titanium. When he was told of Gregor's discovery he investigated Menachanite and confirmed it too contained titanium. It was not until 1910 that M. A. Hunter, working for General Electric in the USA, made pure titanium metal by heating titanium tetrachloride and sodium metal. Why titanium is a successful Bio-material? Titanium is considered so because it promotes good osseointegration. Osseointegration Osseointegration is the direct structural and functional connection between living bone and the surface of a loadbearing artificial implant. A more recent definition defines osseointegration as "functional ankylosis (bone adherence)", where new bone is laid down directly on the implant surface and the implant exhibits mechanical stability. Osseointegration has enhanced the science of medical bone and joint replacement techniques as well as dental implants and improving prosthetics for amputees. Steric Hindrance Steric hindrance is a consequence of steric effects. Steric hindrance is the slowing of chemical reactions due to steric bulk. It is usually manifested in intermolecular reactions, whereas discussion of steric effects often focus on intramolecular interactions. Steric hindrance is often exploited to control selectivity, such as slowing unwanted side-reactions. Implant An implant is a medical device manufactured to replace a missing biological structure, support a damaged biological structure, or enhance an existing biological structure. Medical implants are manmade devices, in contrast to a transplant, which is a transplanted biomedical tissue. The surface of implants that contact the body might be made of a biomedical material such as titanium, silicone, or apatite depending on what is the most functional. In some cases implants contain electronics e.g. artificial pacemaker and cochlear implants. Some implants are bioactive, such as subcutaneous drug delivery devices in the form of implantable pills or drugeluting stents. Internal Fixation for Fractures A broken bone must be carefully stabilized and supported until it is strong enough to handle the body's weight and movement. Until the last century, physicians relied on casts and splints to support and stabilize the bone from outside the body. The advent of sterile surgical procedures reduced the risk of infection, allowing doctors to internally set and stabilize fractured bones. During a surgical procedure to set a fracture, the bone fragments are first repositioned (reduced) into their normal alignment. They are held together with special implants, such as plates, screws, nails and wires. Internal fixation allows shorter hospital stays, enables patients to return to function earlier, and reduces the incidence of nonunion (improper healing) and malunion (healing in improper position) of broken bones. The 
implants used for internal fixation are made from stainless steel and titanium, which are durable and strong. If a joint is to be replaced, rather than fixed, these implants can also be made of cobalt and chrome. Implants are compatible with the body and rarely cause an allergic reaction. Open Reduction Internal Fixation (ORIF) involves the implementation of implants to guide the healing process of a bone, as well as the open reduction, or setting, of the bone. Open reduction refers to open surgery to set bones, as is necessary for some fractures. Internal fixation refers to fixation of screws and/or plates, intramedullary rods and other devices to enable or facilitate healing. Rigid fixation prevents micro-motion across lines of fracture to enable healing and prevent infection, which happens when implants such as plates (e.g. dynamic compression plate) are used. Open Reduction Internal Fixation techniques often are used in cases involving serious fractures such as comminuted or displaced fractures or, in cases where the bone otherwise would not heal correctly with casting or splinting alone. Risks and complications may include bacterial colonization of the bone, infection, stiffness and loss of range of motion, non-union, mal-union, damage to the muscles, nerve damage and palsy, arthritis, tendonitis, chronic pain associated with plates, screws, and pins, compartment syndrome ,deformity, audible popping and snapping, and possible future surgeries to remove the hardware.

Screws are used for internal fixation more often than any other type of implant. Although the screw is a simple device, there are different designs based on the type of fracture and how the screw will be used. Screws come in different sizes for use with bones of different sizes. Screws can be used alone to hold a fracture, as well as with plates, rods, or nails. "After the bone heals, screws can be either left in place or removed". "This project concentrates only on shear strength and torsional strength of the screw so the thread profile is neglected." Types of screws Cannulated screw,Cancellous screw ,Cortical screw, Cortex screw ,Schanz screw ,Lag screw ,Locked screw

Removal of Metal Implants-In some implant recipients, the metal components can cause irritation to the surrounding tissues. This may cause bursitis, tendonitis, or local complications. In these cases, removal of the metal may relieve this irritation. Some of the signs of problematic metal include: - Pain directly at the location of the metal implant - Rubbing of the metal implant underneath the skin - Grinding sensations around the metal implant It can be very difficult to predict if the removal of metal implants will improve symptoms of discomfort. In people who have pain that is clearly caused by the implant, the chance of pain reduction is relatively high. If the pain is more generalized, the chance of resolution is more difficult to predict. The actual process of removing an implant is itself complex.
This is especially true of deep implants that have been in place for a long time. Fractures have been known to occur soon after surgery as the weakened bone collapsed into the drilled hole spaces, particularly in weight-bearing bones of the leg or hip.

\section{PREWORK}

Torsion test on screws in Ansys had projected the stress

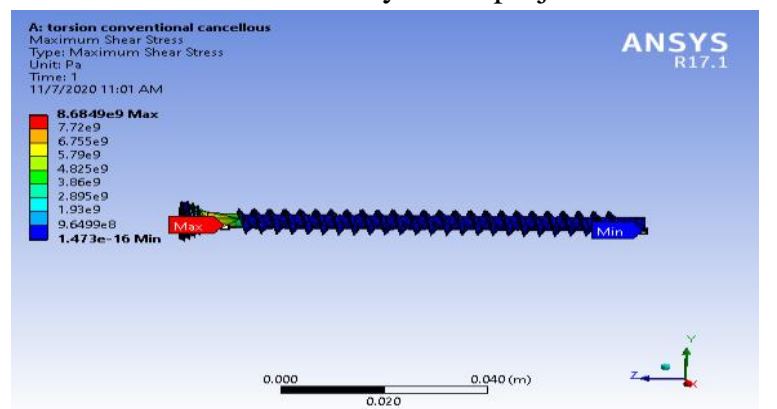

concentration zone in torsion as so

Fig 1 :- Max shear stress-zones in conventional cancellous screws

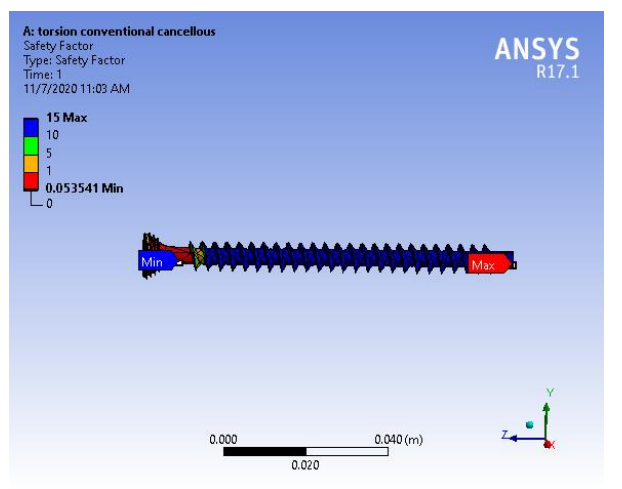

Fig 2:- Factor of safety in torsion of conventional cancellous screw

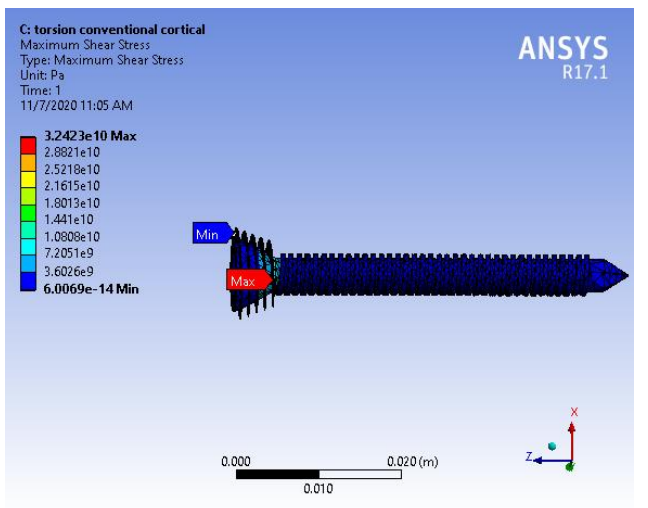

Fig 3 :- Max shear stress zone in conventional cortical screw 
International Journal of Engineering Applied Sciences and Technology, 2021

Vol. 5, Issue 12, ISSN No. 2455-2143, Pages 156-165

Published Online April 2021 in IJEAST (http://www.ijeast.com)

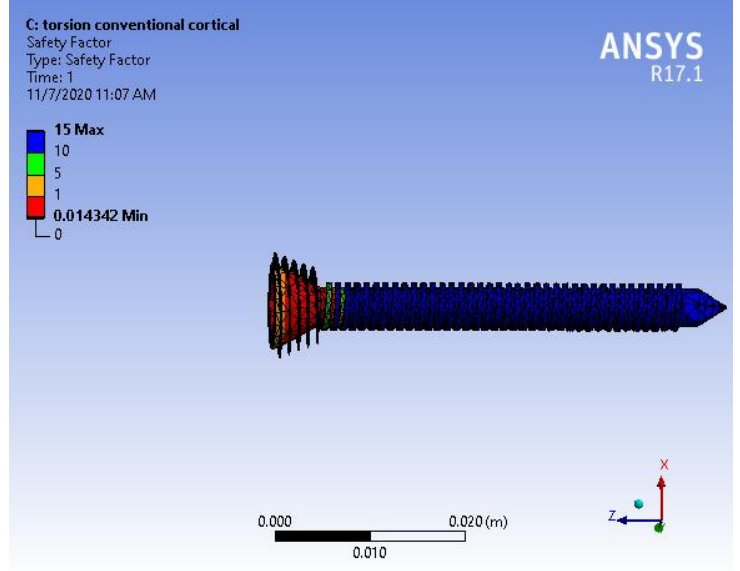

Fig 4 :- Factor of safety in torsion of conventional cancellous screw

My focus

I'm analyzing the Cancellous and Cortical locked head screws .The failure occurred due to torsion while removing implant. Post healing the fracture.

\section{Cancellous screws}

Cancellous bone is a soft spongy bone also called trabecular bone in medical terminology and it is internal tissue which peripheral with cortical bone.

The screws to hold such spongy bone must be specially designed with wide threads

\section{Technicalities of screws}

when the compression plate is to be screwed into the spongy bone the screws must have wide pitch because of the wide spaces between the bone material to obtain a good tight fixture.

The screws which are considered for this project are having

Mass :- 20g

Pitch :- 3mm

Core diameter :- $4 \mathrm{~mm}$

Threaded diameter :- $7 \mathrm{~mm}$

Effective Length :- $72 \mathrm{~mm}$

Mostly the cancellous screws are self taping so the same are considered.

\section{Cortical Screws}

cortical bone is hard structured bone which is more denser to the cancellous bone as it's density is more the cortical screws have short pitch and low depth thread to obtain rigid joint between bone and compression plate.

Screws which are considered in this project are having

Mass :- $12 \mathrm{~g}$

Pitch :- 1mm

Core diameter :- $4 \mathrm{~mm}$

Threaded diameter :- $5 \mathrm{~mm}$

Effective length :- 40mm

\section{Joint design}

Data for design is derived from the internet the website and various books of human bio-mechanics details and other details are mentioned in bibliography.

This joint is considered as bolted joint and the formulas used are from the mechanical design of bolted joints which favors-more for the analysis.

The screws fixed are fatigue tested in Ansys as per the loading directions while walking,squatting and running. This fatigue test results clarified and paved a pathway for further investigation. This concluded that the screws are not as strong as new screws as they are subjected to cyclic loading so the failure is occurring due to fatigue. The torque applied while removal must be less than the torque applied while planting.

\section{Problem statement}

The average human condition is considered for study in which details are
a. height of $6 \mathrm{ft}$
b. weight about $80 \mathrm{KG}$
c. Body-part weight ratio

-Trunk(Chest,back,abdomen)-50.80\%

-Thigh-9.88\%

-Head-7.30\%

-Lower-leg-4.65\%

-Upper-arm-2.7\%

-Forearm-1.60\%

-Foot-1.45\%

-Hand-0.66\% 
d. All other health conditions and parameters are considered normal to make clear cut Idea so that analysis is only against to the engineering defects of implant.

\section{NO OTHER MEDICAL COMPLICATIONS ARE CONSIDERED.}

\section{Types of forces}

Both plate and screws collectively carry shear force of magnitude of $67.96 \%$ of body weight in negative $\mathrm{Y}$ direction which produces the reaction in positive $\mathrm{Y}$ direction and $15.98 \%$ force in positive $\mathrm{Y}$ direction which produces the reaction in negative $\mathrm{Y}$ direction.

\section{Alignment of femur bone and various axis.}

there are three main axis associated with femur bone they are

\section{Anatomic-axis \\ 2 Mechanical-axis \\ 3 Joint line-axis}

Anatomic axis is the line drawn through the center line of the femur bone. This suspends an angle of 6 degrees with the mechanical axis in normal conditions.

Mechanical axis is the line drawn perpendicular from the tibia in normal conditions.

Joint line this is the line drawn joining the mechanical axis and the bottom of the femur. A perpendicular is projected up from joint line such that it suspends an angle of 3 degrees with mechanical axis.

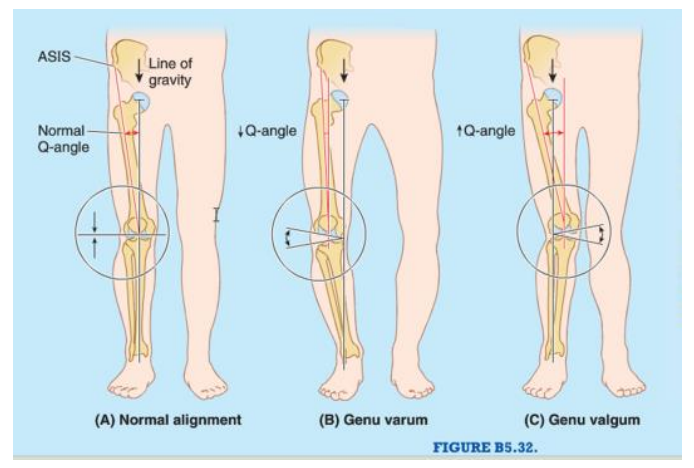

Fig 9 : Representation of other abnormal conditions

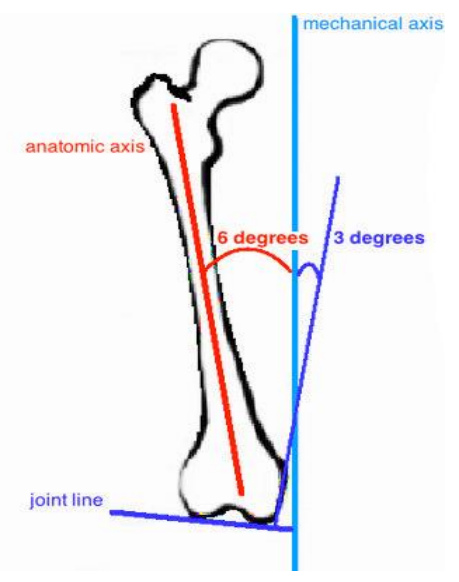

Fig 8 : various axis associated with femur bone

\section{Case of Failure}

Failure is observed to occur when there is abnormality of alignment of the bone with the above mentioned axis the misalignment may occur while undergoing physiotherapy post fracture fixation. There is a chance that this can lead to bending of the screw inside the body.

\section{Resolution of forces on the screw-plate assembly}

assuming fracture occurs above tibia at the weak portion of femur.

Based on above axis the shear forces on the bone are resolved as shear forces in negative and positive directions magnitude of both forces are considered for 3 different cases.

\begin{tabular}{|c|l|l|}
\hline $\begin{array}{c}\text { Force } \\
\text { total } \\
\text { weight of } \\
\text { human } \\
\text { body) }\end{array}$ & $\begin{array}{l}-\mathrm{Y} \text { in } \\
\mathbf{6 7 . 9 6 \%} \\
\text { of body } \\
\text { weight } \\
\text { in } \\
\text { Newtons }\end{array}$ & $\begin{array}{l}+\mathrm{Y} \text { in } \\
\mathbf{1 5 . 9 8 \%} \\
\text { of body weight } \\
\text { in } \\
\text { Newtons }\end{array}$ \\
\hline $0.78 \mathrm{KN}$ & 530.08 & 124.64 \\
\hline $0.88 \mathrm{KN}$ & 598.05 & 140.62 \\
\hline $0.98 \mathrm{KN}$ & 666.01 & 156.6 \\
\hline
\end{tabular}

Table depicting magnitude of forces

as they are perpendicular to the mechanical axis they are aligned oblique to anatomic axis so there is unconventional alignment which may give rise to undesired stresses in the screws in both $\mathrm{X}$ and $\mathrm{Y}$ directions which will lead to generation of tensile and shear stresses. Fatigue analysis is carried out in ansys to get a clear idea of the fatigue developed in the screws for further progress of this investigation.

\section{Metallurgical factors leading to failure with proofs}

\section{Design Factor regarding diameter}

On increasing the diameter the fatigue life of screw increases but increase in dimensions makes screw unfit for fixation into the plate the increase in hole size of the plate,weakens the plate and again it may lead to a catastrophe so its better to improve the strength of the screw or to find a remedy for effective removal 
As the screw design is conventional this investigation led to redesigning of the screws with extended grooves for application of torque while fixing and removal the analysis of the conventional screws resulted in failure due to improper transformation of torque.

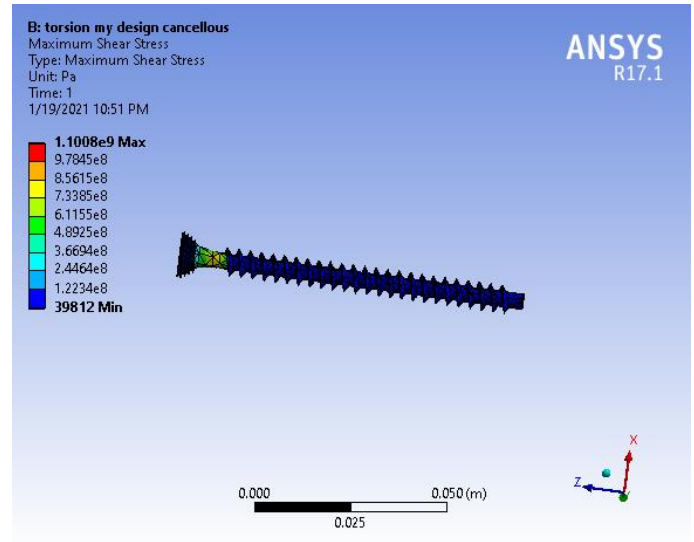

Fig 16 : Torsional analysis of new design cancellous screw

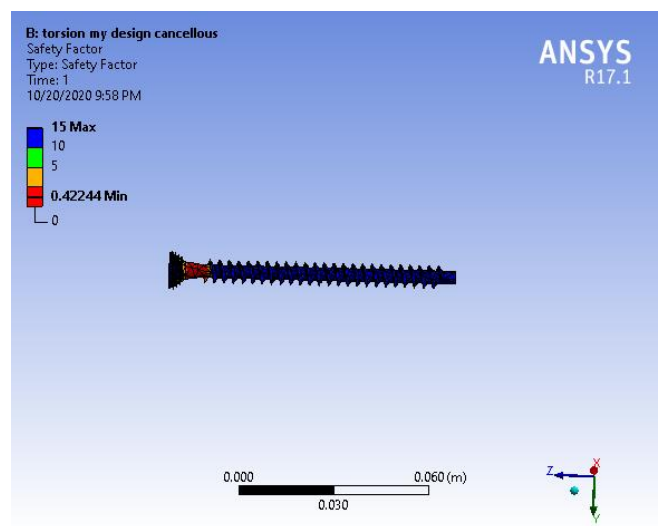

Fig 17 : Torsional analysis of new design cancellous screw Factor of safety

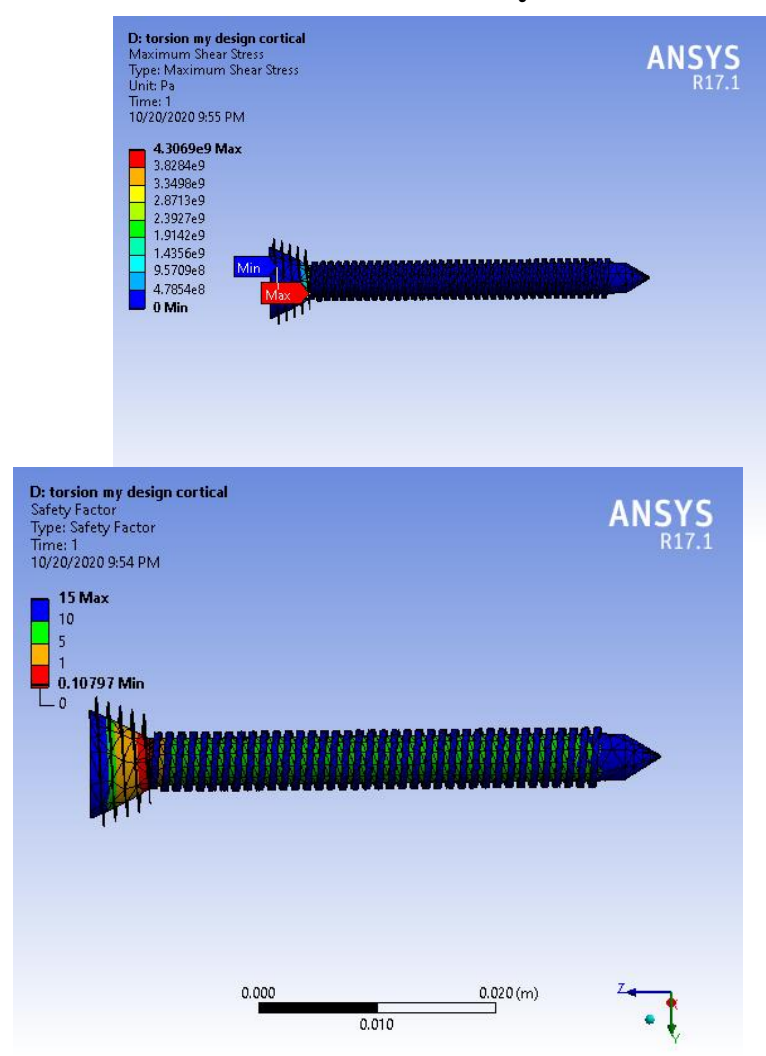

Fig 18 : Torsional analysis of new design cortical screw

Fig 19 : Torsional analysis of new design cortical screw Factor of safety

New design vs Old design

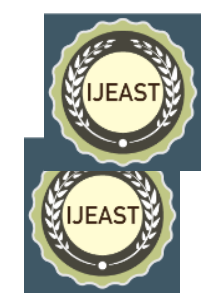

Cancellous screw

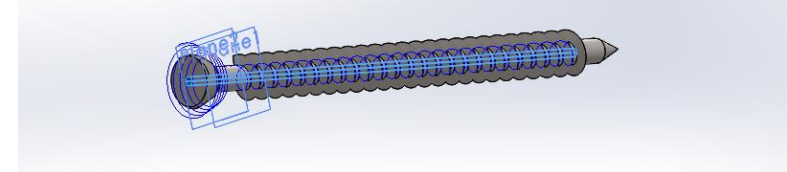

Fig 20 : conventional cancellous screw groove Fig 21 : My design cancellous screw groove

\section{Cortical screw}

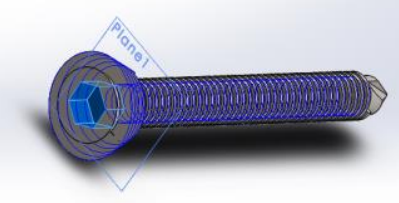

Fig 22 : conventional cortical screw groove 


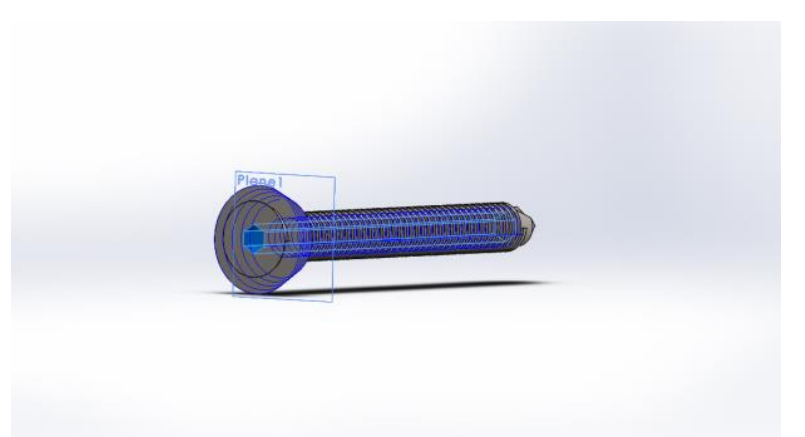

Fig 23 : My design cortical screw groove

This modification of screw-groove had reduced the torsional stress near the neck and shank connection this also improved the safety factor of screw in torsion as the results are displayed above but there is a reduction in shear strength because of the total hollowness produced by the groove in the shank probably it can be neglected as the fractured area will not be subjected to high of stresses.

By the concept of torsion in shafts this design is feasible as the hollow shaft transfer more torque than solid shaft also the torsional shear stress magnitude in both cases i.e conventional and new design concluded the same.

\section{Fatigue}

This fatigue play an important role while removing an implant its clear from ansys analysis that the screws are subjected to fatigue loading and their life got effected now they wont support the torque applied for removal and also the development of bone play a key role in application of higher torque than applied for planting the implants. It is observed that the fatigue on the screws is low cycle high stress type this fatigue also imparts stresses in the screws which may lead to deformation of the shape of the screws and this creates a worst scenario while removal of the implants. On increasing the size and diameters of the screws we can increase the fatigue life of the screw but this will lead to re designing of the screw-plate which may give rise to some other complications.

Two types of fatigue is observed (i) Torsional fatigue(ii) Bending fatigue

As the torsional application is very less when compared to bending so torsional fatigue is neglected.

\section{Fatigue calculation of the screw}

This is the estimation of endurance limit using the Good man criterion this is the equation which relates the ultimate tensile strength,endurance limit and factor of safety with stress amplitude and mean stress.

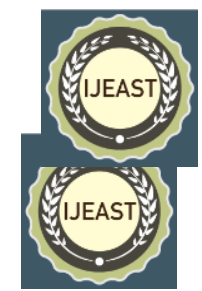

The endurance limit obtained for conventional screws is observed to be high than the endurance limit of the new design so this shows that the new deep groove screw may fail in even more less number of cycles than the conventional screw. The factor of safety is considered to be same for both the designs.

This can be taken over by some heat treatments and further grain refining treatments which improves the shear strength of the screw.

\section{Goodman equation}

$\square \mathrm{m} / \square$ ut $+\square$ amp $/ \square$ end $=\mathbf{1} / \mathbf{F O S}$

\begin{tabular}{|c|c|c|c|}
\hline $\begin{array}{l}\text { S. } \\
\mathbf{N} \\
\mathbf{0}\end{array}$ & Parameter & Conventional & My design \\
\hline 1 & $\begin{array}{l}\text { Max shear } \\
\text { stress } \\
(\mathrm{MPa})\end{array}$ & 1.4 & 1.41 \\
\hline 2 & $\begin{array}{l}\text { Min shear } \\
\text { stress } \\
(\mathrm{Pa})\end{array}$ & 7.03 & 11.41 \\
\hline 3 & $\begin{array}{c}\text { Stress } \\
\text { amplitude } \\
(\mathrm{MPa})\end{array}$ & 6.97 & 7.03 \\
\hline 4 & $\begin{array}{l}\text { Mean stress } \\
\quad(\mathrm{MPa})\end{array}$ & 6.98 & 7.03 \\
\hline 5 & Safety factor & 3 (assumed) & 3 (assumed) \\
\hline 6 & $\begin{array}{c}\text { Endurance limit } \\
\text { obtained } \\
(\mathrm{MPa})\end{array}$ & 21.51 & 21.69 \\
\hline
\end{tabular}

Table depicting various stresses in cancellous screw

\section{Cortical screw Fatigue}


International Journal of Engineering Applied Sciences and Technology, 2021

Vol. 5, Issue 12, ISSN No. 2455-2143, Pages 156-165

Published Online April 2021 in IJEAST (http://www.ijeast.com)

\begin{tabular}{|c|c|c|c|}
\hline $\begin{array}{c}\text { S. } \\
\mathbf{N} \\
\mathbf{0}\end{array}$ & Parameter & Conventional & My design \\
\hline 1 & $\begin{array}{c}\text { Max shear stress } \\
(\mathrm{MPa})\end{array}$ & 213.3 & 283.2 \\
\hline 2 & $\begin{array}{c}\text { Min shear stress } \\
(\mathrm{MPa})\end{array}$ & 0 & 0 \\
\hline 3 & $\begin{array}{c}\text { Stress amplitude } \\
(\mathrm{MPa})\end{array}$ & 106.65 & 141.6 \\
\hline 4 & $\begin{array}{c}\text { Mean stress } \\
\text { (MPa) }\end{array}$ & 106.65 & 141.6 \\
\hline 5 & $\begin{array}{c}\text { Safety factor } \\
\text { Endurance limit } \\
\text { obtained (MPa) }\end{array}$ & 544.56 & 853.14 \\
\hline
\end{tabular}

Table depicting various stresses in cortical screw

Graph depicting the ultimate limit and endurance limit
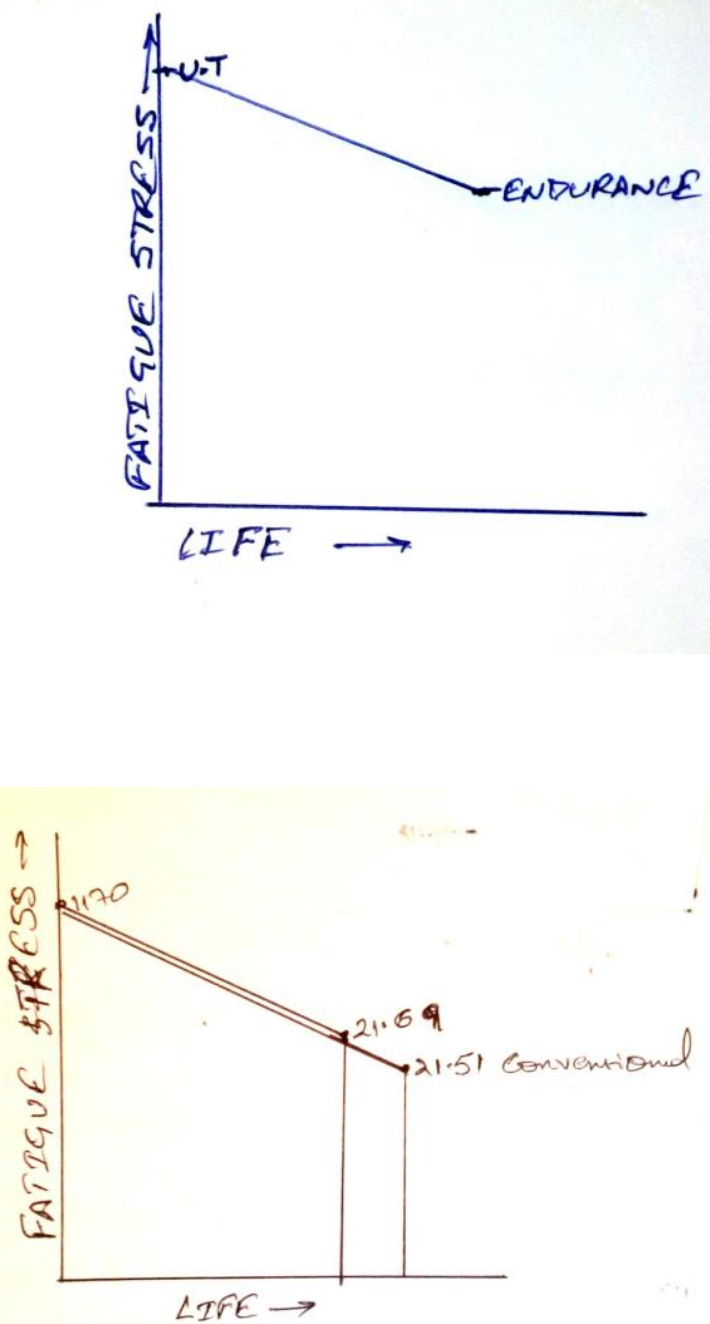

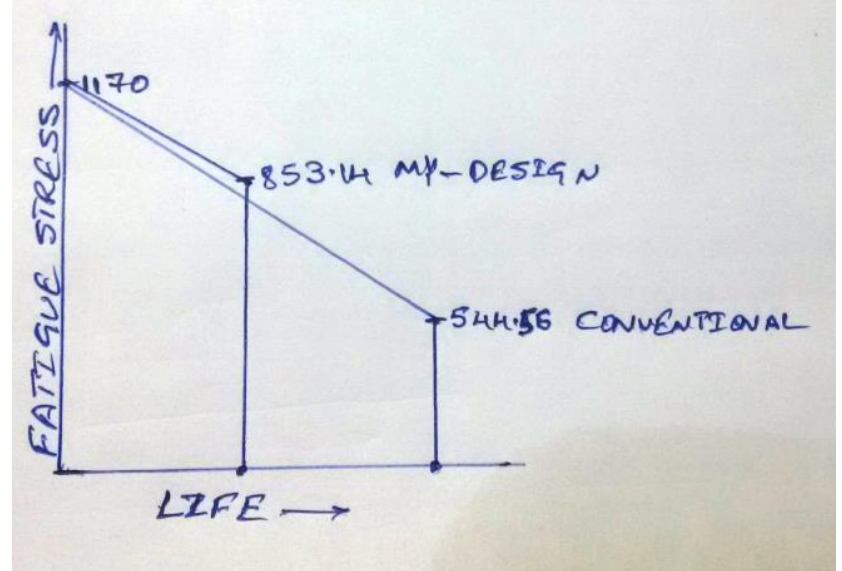

\section{Graph of cancellous screw Fatigue}

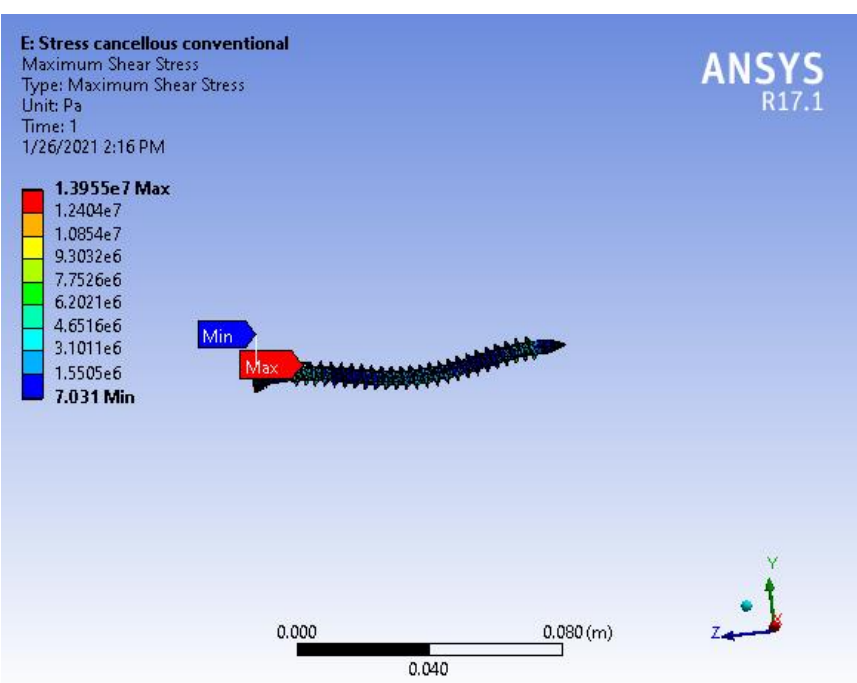

Graph of cortical screw

Cancellous screws stress analysis results

Fig 10 : maximum to minimum shear stress-zones in conventional cancellous screw 
International Journal of Engineering Applied Sciences and Technology, 2021

Vol. 5, Issue 12, ISSN No. 2455-2143, Pages 156-165

Published Online April 2021 in IJEAST (http://www.ijeast.com)

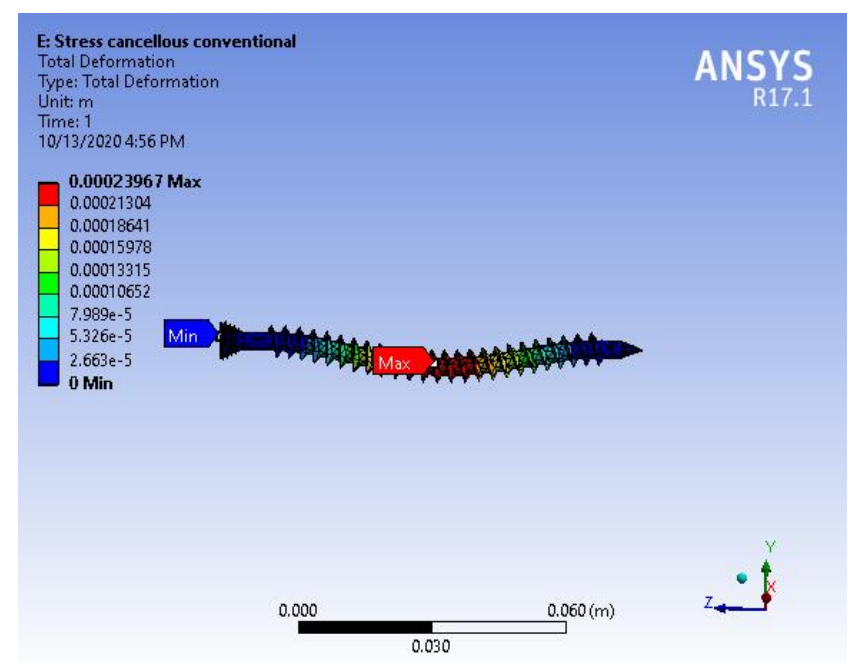

Fig 12 : Total deformation of conventional cancellous screw under shear stress

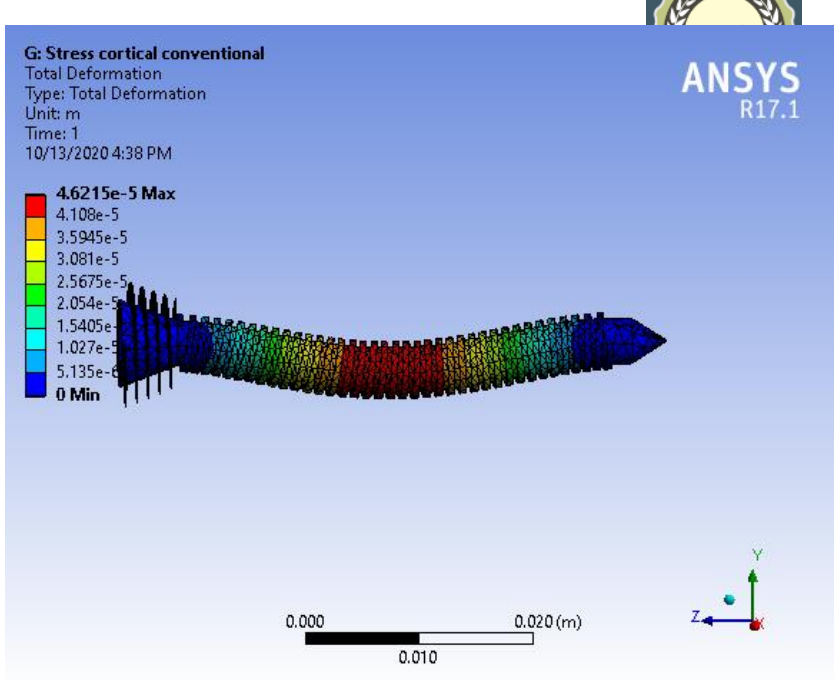

Fig 14 : Total deformation of conventional cortical screw under shear stress

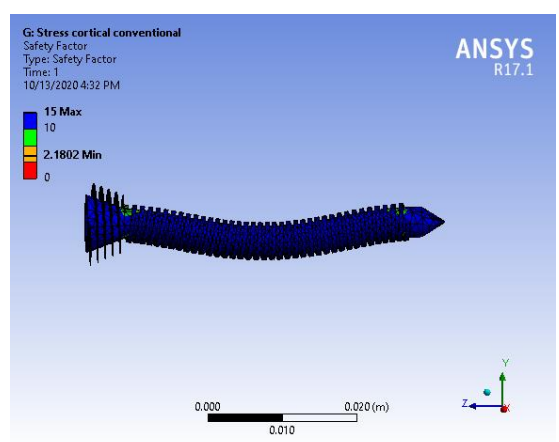

Fig 15 : factor of safety of conventional cortical screw under shear stress

Design data of conventional and new design

Cancellous Screw

\begin{tabular}{|l|l|c|c|}
\hline $\begin{array}{l}\text { S. } \\
\text { No }\end{array}$ & $\begin{array}{l}\text { SPECIFICATI } \\
\text { ON }\end{array}$ & $\begin{array}{l}\text { CONVENTI } \\
\text { ONAL }\end{array}$ & MY DESIGN \\
\hline 1 & $\begin{array}{l}\text { Effective Length } \\
(\mathrm{mm})\end{array}$ & 72 & 72 \\
\hline 2 & $\begin{array}{l}\text { Pitch } \\
(\mathrm{mm})\end{array}$ & 3 & 3 \\
\hline 3 & $\begin{array}{l}\text { Core diameter } \\
(\mathrm{mm})\end{array}$ & 4 & 4 \\
\hline 4 & $\begin{array}{l}\text { Groove length } \\
(\mathrm{mm})\end{array}$ & 5 & 70 \\
\hline 5 & $\begin{array}{l}\text { Groove diameter } \\
(\mathrm{mm})\end{array}$ & 4.3 & 2 \\
\hline
\end{tabular}

Table depicting new cancellous screw parameters

Fig 13 : maximum to minimum shear stress-zones in conventional cortical screw 
International Journal of Engineering Applied Sciences and Technology, 2021

Vol. 5, Issue 12, ISSN No. 2455-2143, Pages 156-165

Published Online April 2021 in IJEAST (http://www.ijeast.com)

\section{Cortical Screw}

\begin{tabular}{|l|l|c|c|}
\hline $\begin{array}{l}\text { S. } \\
\text { No }\end{array}$ & $\begin{array}{l}\text { SPECIFICATI } \\
\text { ON }\end{array}$ & $\begin{array}{c}\text { CONVENTI } \\
\text { ONAL }\end{array}$ & MY DESIGN \\
\hline 1 & $\begin{array}{l}\text { Effective Length } \\
(\mathrm{mm})\end{array}$ & 40 & 40 \\
\hline 2 & $\begin{array}{l}\text { Pitch } \\
(\mathrm{mm})\end{array}$ & 1 & 4 \\
\hline 3 & $\begin{array}{l}\text { Core diameter } \\
(\mathrm{mm})\end{array}$ & 4 & 40 \\
\hline 4 & $\begin{array}{l}\text { Groove length } \\
(\mathrm{mm})\end{array}$ & 5 & 2 \\
\hline 5 & $\begin{array}{l}\text { Groove diameter } \\
(\mathrm{mm})\end{array}$ & 4.3 & \\
\hline
\end{tabular}

Table depicting new cortical screw parameters

\section{Discussions on results}

Varying the groove depth had increased the torsional strength and also the factor of safety but finally it decreased the shear strength and the fatigue life. Hopefully there will be no effect with decrease in the fatigue life as the operated area will not be subjected to shear stress more to limit as decreasing the ratio of area to depth ratio will be more effective but not feasible after certain limit practically

This screw planting procedure must be standardized else there is huge chances of failure if not treated properly and the screw must be in-line axis with the plate along with which it is planted this may lead to alteration of stress angle and the screw may fail.

\section{All About Cad-Cam Of Project}

\section{Solid Works}

Dassault systems had developed a very good and effective tool for computer aided drafting of the screws without which it would be a tough task for me to go around the foundries for project work being accomplished this helped me in cost effective designing the screws without any deviations from the required dimensions.

This software also had various cutting edge facilities for drafting any of the mechanical components and they also provided a analysis tool which helps to understand the flaws in design and modify against them.

\section{Ansys}

Ansys.inc It's a well known tool for computer aided analysis this is a smart tool in-fact we can call it an NDT tool as it will do work without destruction of the specimen. This is sophisticated and trust worthy analysis tool which can estimate

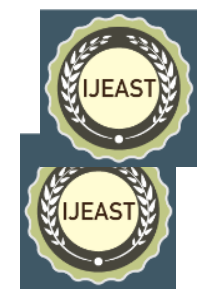
various kinds of analysis factors such as safety factor,3Dstress, deformation produced, creep and the fatigue this is a cost effective method of analyzing the behavior of mechanical component subjected to both static and dynamic loading. In my work I drafted the screw in solid works and analyzed it in the Ansys.

\section{Analysis in workbench}

Drafted screw is loaded in to Ansys workbench where its analyzed simulating the extreme conditions favoring the screw failure. Torsional analysis is carried out by fixing the whole shank part of the screw and applying a torsional stress of $1000 \mathrm{~N}$ on the head of the cancellous and cortical of conventional type screw and the result obtained are projected in the figure and similarly the new design screw is also simulated to same conditions and analyzed and the results are projected in the figure

For shear stress analysis the -ve $\mathrm{Y}$ force is applied on the whole of the shank while +ve $\mathrm{Y}$ force is applied near the head of the screw and the end tip of the screw and the obtained results are projected in the fig

Meshing is done using the auto-mesh tool because of alteration of the meshing may occur to simulate and compare the conventional and new design.

Care is taken to simulate almost the similar and extreme conditions of the screw inside the human body to prevent other technical ambiguities post processing of the analysis. The results obtained are also compared accordingly so that they will be much clarified in terms of stresses, deflections, safety factors etc.

\section{Scope for further Research}

\section{Melting}

This is the only method which can be employed to remove the failed screw (broken or bent screw ) which must be done on controlling various factors but still needs a more research but as far as my project concerned I am focused on melting the Titanium at the rate at which the titanium melts to promote lower conductivity of the bone while melting. At lower temperatures by varying the other thermodynamic entities.

\section{Problems associated with melting of Titanium}

The titanium is preferred in industrial application because of it's high melting point there is a very good chance of ignition and combustion when the titanium is heated vigorously due to presence of oxide film so the implant 
design must be engineered heavily to prevent the titanium fire. Thermal necrosis is one more factor to be controlled or it may result in severe damage to tissues around the melted area.

\section{Engineering the melting process of titanium}

This involves calculations of heat transfer from heat source to the broken implant. In this dissertation the screw is considered as a solid cylinder and the heat transfer in cylindrical coordinates is considered. As the Titanium melting point is concerned it lies at $1668^{\circ} \mathrm{C}$ so in-order to melt the titanium implant heat must be supplied at $1668^{\circ} \mathrm{C}$. Here arises the question of necrosis control, at $55^{\circ} \mathrm{C}$ necrosis occur within a span of 10 seconds so at $1668^{\circ} \mathrm{C}$ thermal necrosis occur even more rapid i.e in $1 / 3 \mathrm{rd}$ second according to arithmetic decrement law.

Implementation of the melting process by controlling the temperature using various factors this paves a path way for development of a mechanical tool which spontaneously melts and vacuum the liquid metal soon after melting before the necrosis of bone occur and this will also lead to development of the cryoprobe for bone to prevent the thermal conductivity and prevent necrosis for a moment to facilitate melting.

Metallurgical modifications or treatments like heattreatments grain refinement etc can be done in orfer to improve the fatigue life.

\section{BIBLIOGRAPHY}

1. course Metallurgical Failure Analysis M.Tech (J N T U-Kakinada)

2. Course Advanced Metallurgical thermodynamics M.Tech (J N T U-Kakinada)

3. Textbook of Advanced metallurgical Thermodynamics by Ahindra Ghosh.

4. course MECHANICAL ENGINEERING DESIGN B.Tech (K L University)

5. G Clay Taylor(DPM) Donald R Green (DPM) -Complications of internal fixation a journal from podiatry institute

6. Mihra S. Taljanovic, MD • Marci D. Jones, MD • John T. Ruth, MD James B. Benjamin, MD • Joseph E. Sheppard, MD • Tim B. Hunter, MD-Fracture Fixation 1

7. Naresh Chaudhary, Scott T. Lovald, Jon Wagner, Tariq Khraishi, and Bret Baack Manufacturing Engineering Program, University of New Mexico, Albuquerque, NM 87131, USA Mechanical Engineering Department, University of New Mexico, Albuquerque, NM 87131, USA
Department of Surgery, University of New Mexico, Albuquerque, NM 87131, USA---Experimental and

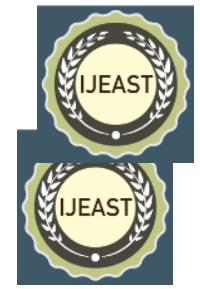
Numerical Modeling of Screws Used for Rigid Internal Fixation of Mandibular Fractures.

8. Kenneth A. Egol, MD, ${ }^{*}$ Erik N. Kubiak, MD,* Eric Fulkerson, MD,* Frederick J. Kummer, PhD,* and Kenneth J. Koval, MD--Biomechanics of Locked Plates andScrews

9. Classical Mechanics and Human Movement by Aydin Tozeren (for human body-part weight ratio)

10. http://www.actabio.pwr.wroc.pl/Vol4No2/1.pdf (for the study of thermal necrosis)

11. Merk, Bradley R.; Stern, Steven H.; Cordes, Scott; Lautenschlager, Eugene P.*--A Fatigue Life Analysis of Small Fragment Screws

(for fatigue testing process and clarification regarding conclusions)

- https://en.wikipedia.org/wiki/Osseointegration .

- https://www.cnclathing.com/guide/titanium-vssteel-whats-the-difference-titanium-and-steelcomparison- cnclathing (properties of titanium)

- https://community.sw.siemens.com/s/article/whatis-a-sn-curve ( $\mathrm{Sn}$ curve clarifications) 